Article

\title{
The Quest for Adaptation through Spatial Planning and Ecosystem-Based Tools in Resilience Strategies
}

\author{
Konstantina-Dimitra Salata *(D) and Athena Yiannakou (1) \\ School of Spatial Planning and Development, Faculty of Engineering, Aristotle University of Thessaloniki, \\ GR-54124 Thessaloniki, Greece; adgianna@plandevel.auth.gr \\ * Correspondence: salatadg@plandevel.auth.gr
}

Received: 10 June 2020; Accepted: 7 July 2020; Published: 9 July 2020

\begin{abstract}
As climate change and other interdependent challenges are expected to become increasingly acute and unpredictable, so the need for policies and measures to reduce risks and uncertainties in order to adapt to these changes becomes more imperative. Cities can influence their adaptation, resilience, and eventually their sustainability through spatial planning with the use of more ecosystem-based planning tools, such as Green Infrastructure (GI). The present paper is an attempt to assess whether and how city strategies address the objective of an adaptation which interconnects the criteria of vulnerability, adaptability, and resilience through spatial planning. For this purpose, the paper examines the Resilience Strategies of seven European cities of the 100 Resilient Cities initiative (100RC). Based on a thematic analysis, the paper investigates whether these strategies incorporate a spatial planning approach which contributes to adaptation to climate change, focusing on GI as a spatial planning tool. The paper argues that there is room for improvement in all the examined strategies, as none of them fully incorporate the concept of GI, and, furthermore, that some critical planning principles which contribute to adaptation are missing.
\end{abstract}

Keywords: adaptation; climate change; spatial planning; Resilience Strategies; ecosystem-based planning tools; Green Infrastructure; European cities

\section{Introduction}

In recent years, the concept of resilience has gained increasing prominence within diverse disciplines. It has become an important goal for cities in a number of policy domains, such as climate change adaptation and mitigation, as well as within spatial planning. This is evidenced by a growing number of governmental and non-governmental reports, initiatives, plans, and policies [1-6] which have tried to achieve general resilience for urban areas. Resilience is not a new concept, although it may be a comparatively recent one in the field of spatial planning and urban design. Despite the extensive and growing proliferation of its uses and the multiplicity of its definitions, resilience still remains a fuzzy and contested concept $[2-4,7,8]$. Some authors have even argued that resilience might have become a buzzword and has perhaps lost any real meaning for spatial planning [2,3,7]. Others have observed that resilience seems to be gradually replacing the concepts of sustainability and adaptation, with cities using resilience rather than adaptation strategies to prepare for and address climate change impacts [2,4].

These ambiguities make it difficult both to measure and evaluate resilience and to apply concrete spatial planning policies which lead to resilience. Different theoretical and empirical approaches have emphasized different elements of urban development and, hence, different aspects of urban resilience. Therefore, the theoretical connections between these aspects still remain weak $[1,5,8]$. The lack of consensus regarding both the characteristics and the measurement of resilience is reflected in the diverse range of goals and objectives that cities have aimed to achieve through their strategies for 
resilience [1]. However, some common themes and key characteristics of resilient cities have been proposed, and a large part of the relevant literature argues that resilience is essential for achieving climate change adaptation and mitigation [1,4].

Apart from resilience, several other complementary scientific terms and concepts have been used in order to comprehend adaptation to climate change. These include "vulnerability", "exposure", "sensitivity", "adaptability", "stability", "robustness", and "flexibility" [2,9-11]. The concepts themselves, as well as the nature of their interrelationships, are unclear. There are a considerable number of overlapping definitions, as their interpretation largely depends on subjective factors, such as the authors' scientific background. This is true specifically with reference to the concepts of resilience, vulnerability, and adaptability. While they are considered to be related concepts, the precise nature of their interrelationship remains obscure. However, it has been suggested that vulnerability and resilience are linked through adaptability, and that the key determinants identified as increasing adaptability are also the ones said to increase resilience and decrease vulnerability. These common determinants comprise all forms of capital (social, human, natural, physical/built, and economic), as well as the system of governance [9,12-19].

Potentially, spatial planning and chiefly land use planning can increase a city's resilience and adaptability while decreasing its vulnerability. It can do this because it regulates land development and the uses of the built up and open/green areas, essentially influencing a city's adaptation and eventually its sustainability [20-26]. It is argued that an eco-system approach to planning, and in particular the use of GI, can contribute to these objectives through the promotion of diversity, connectivity, redundancy, flexibility, and modularization, along with the encouragement of learning, participation, partnership, multi-level governance, and complex adaptive system thinking [24,25,27,28]. Green Infrastructure (GI) essentially refers to a multifunctional network of environmental and other assets, public and private, existing and new. Such assets include street trees, green roofs and walls, private gardens, pedestrian and cycle routes, road and railway networks, pocket parks, city parks, regional or national parks, churchyards, school grounds, play areas, local nature reserves, sports pitches, allotments, vacant and derelict land, agricultural land, ponds/lakes, rivers, and floodplains. This network covers all spatial scales, while its design and management respects and enhances the local character of the area [29-31]. It is therefore evident that such an approach links the concept of GI directly or indirectly to spatial planning, both from a physical as well as an institutional perspective.

The present paper attempts to assess whether and how city strategies address the adaptation objectives which interconnect vulnerability, adaptability, and resilience through spatial planning. For this purpose, the paper examines the Resilience Strategies of seven European Cities which have been drafted under the 100 Resilient Cities initiative (100RC), pioneered by the Rockefeller Foundation. Based on a thematic analysis, the paper investigates whether these strategies incorporate a spatial planning approach which contributes to the process of adaptation to climate change. Specifically, the GI planning tool will be examined in order to attempt to establish whether its use in these cities' Resilience Strategies integrates specific spatial planning actions and measures designed to deal with the hazards of climate change. The particular focus of this analysis will be on how these actions and measures address the phenomena of the urban heating and flooding. The findings of the empirical study highlight the extent to which different urban strategies can contribute to the process of adaptation to climate change, and to what extent spatial planning policy and tools inform these strategies.

\section{Methodology}

This paper considers adaptation as an umbrella concept which includes three interconnected concepts: vulnerability, resilience, and adaptability (as the link between the two latter [18]) (Figure 1). The paper also adopts an evolutionary perspective of resilience [2], viewing it as a continuous process of transformation and adjustment aimed at adaptation and, ultimately, sustainability. Essentially, resilience concerns our response to uncertainty through adaptability and adjustment within what has been called a "stability landscape" [14]. Such adaptation can lead either to a return 
to the previous state of equilibrium or to a transition to an alternative state. This transformation (i.e., transition to a different stability landscape) can create a new regime with enhanced resilience. In this way, the adaptation of socio-ecological systems (SES), such as cities, can be continuous.

vulnerability: the degree to which a system is susceptible to, or unable to cope with, adverse effects of climate change; it has an external (exposure) and internal (sensitivity and adaptability) dimension

resilience: the ability of complex SES to change, adapt and transform in response to hazards including those associated with climate change; it is considered to be closely related with adaptability

adaptability: the ability or capacity of a system to adjust to climate change, to moderate potential damages, to take advantage of opportunities, or to cope with the consequences, by modifying/changing its characteristics or behaviour so as to cope better with existing or anticipated hazards; it is considered as requirement that enables adaptation and sustainability and serves as the link between vulnerability and resilience

adaptation: a process, action or outcome in a system in order to better cope with, manage or adjust to actual or expected changing conditions (stresses, hazards, risks), to moderate harm or exploit beneficial opportunities and so attain a desirable configuration and sustainability

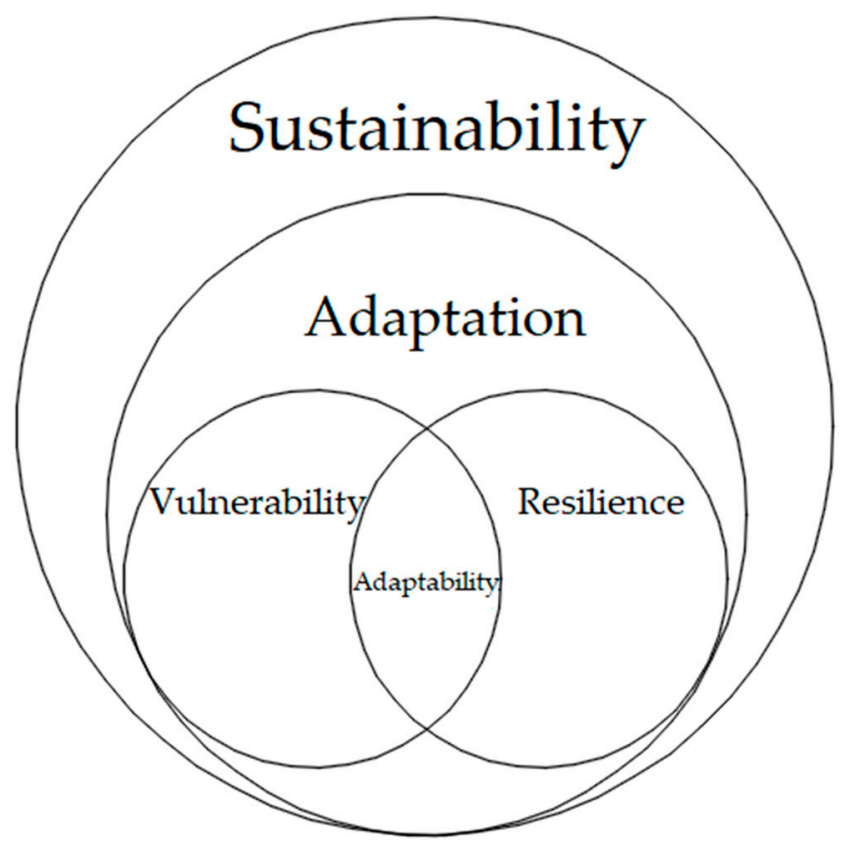

Figure 1. Adaptation as an umbrella concept and the interconnected concepts of vulnerability, resilience, and adaptability (based on $[2,9,11,12,14,17-20]$ ).

In the present study, a qualitative analysis was carried out on the "Resilience Strategies of European Cities" dataset. We chose to investigate the Resilience Strategies of the 100RC initiative, because the drafting of all these strategies is based on the same methodology. The strategies chosen for this study were selected according to criteria which would facilitate their comparison and from which substantial conclusions could be drawn. Therefore, the research includes those European cities' strategies that were completed by the end of 2018, as well as those that have a relatively medium-term outlook. More specifically, the dataset is comprised of seven cities-Veille (Denmark), Rotterdam (Netherlands), Glasgow (UK), Thessaloniki and Athens (Greece), Paris (France), and Rome (Italy) —all of which have both a medium- and a longer-term perspective. In contrast, the Resilience Strategy of Bristol (UK) was excluded, as it has only a long-term vision (until 2066). Thus, the research focused on the strategies of European cities which, despite their differences, share critical common objectives in shaping their spatial planning [32].

The deductive thematic analysis based on the theoretical framework outlined above incorporated the "six-phased process" pioneered by Braun and Clarke [33]. The main objective of the thematic analysis was to investigate whether these cities are using, or planning to use, GI as a basis for adaption to the hazards and risks of the urban heat island (UHI) effect and of flooding due to heavy rainfall or rising sea levels. Adaptation to climate change was assessed through vulnerability, resilience, and adaptability. This investigation focused on both the internal and external dimensions of vulnerability, namely "sensitivity and adaptability" and "exposure", respectively. In regard to exposure to climate change, the study examined whether the phenomena of urban heating (increased temperatures along with UHIs) and flooding (caused by heavy rainfall, flash flooding, and rising sea and river levels) were identified as shocks or stresses by the strategies themselves in the same way as other social and economic factors were identified. It is worth noting that the hazards identified in these strategies are based on the estimations and opinions of both experts and citizens according to the methodology provided by the 100RC initiative. 
Theorists have argued that GI addresses both of these climate hazards. Sensitivity is an inherent property of socio-ecological systems which depends on their characteristics and properties [15,34]. Thus, the paper examines whether cities' Resilience Strategies maintain and enhance the existing GI assets and/or propose the creation of new ones. The present study examined the degree of both adaptability and resilience embodied within a particular strategy's key pillars and measures from the perspective of spatial planning, taking into account different forms of capital. Specifically, the study examined whether the strategies provided the development of a number of critical determining factors, "determinants", which relate to both the physical as well as institutional perspective of spatial planning (Table 1):

- connectivity among GI assets;

- enhancement/protection or creation of different GI assets (diversity);

- the occupancy of available spaces according to a variety of uses and functions, and the providing of multiple benefits by each asset (multifunctionality);

- $\quad$ an increase in public information/education and awareness training, along with the exchange of both scientific knowledge and knowledge of best practices, generated and transferred for other cities initiatives. These knowledge exchanges concern various partners, including citizens;

- the participation of and collaboration between partners, including citizens;

- multi-level governance.

Table 1. Evaluation determinants.

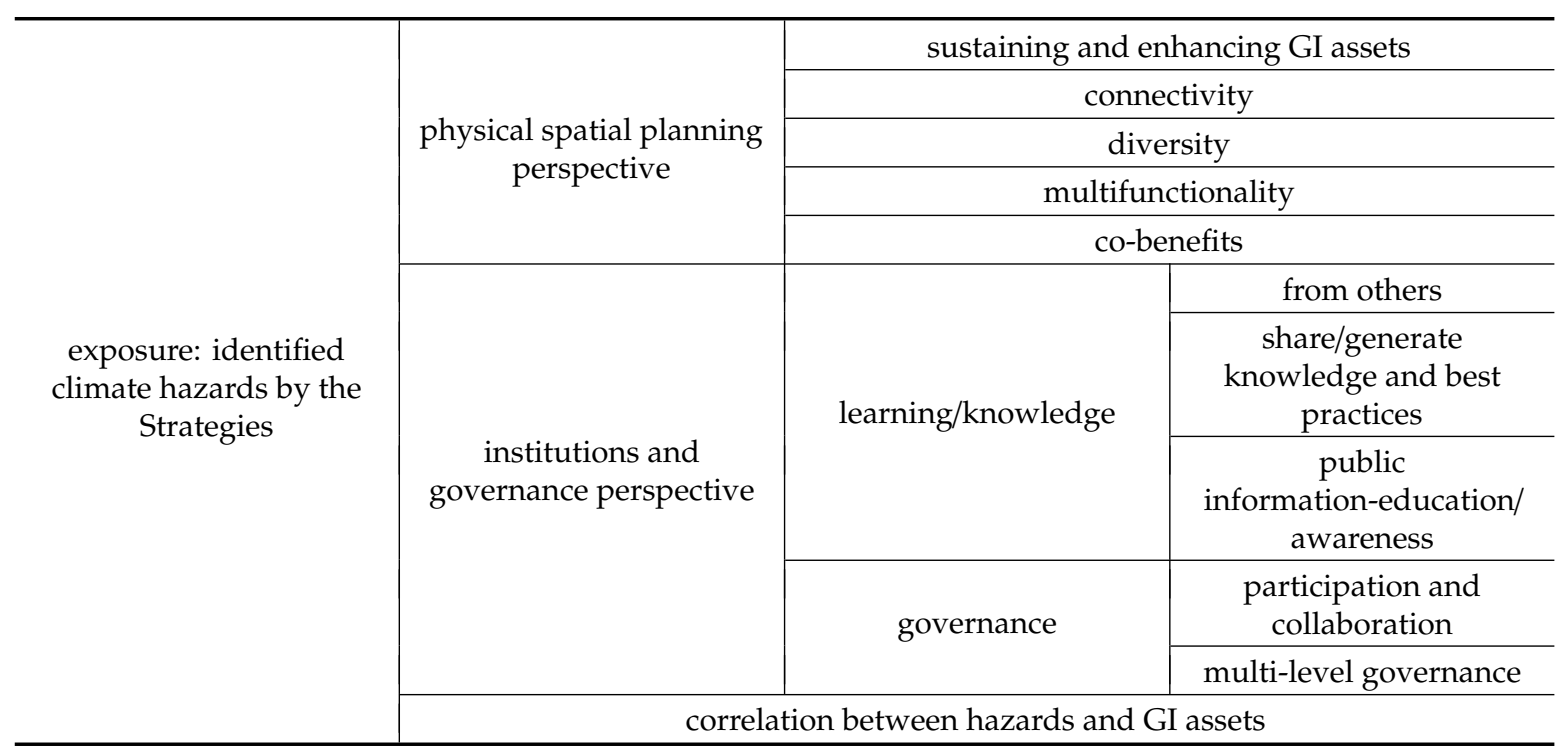

Finally, the study assesses whether the identified hazards are addressed by using GI assets (correlation between hazards and GI assets).

Regarding the two latter determinants, the study took both their vertical and the horizontal dimensions into consideration. In this regard, the study examined whether higher and lower levels of partners, as well as local stakeholders, contributed to the design and the implementation of the proposed actions. Local stakeholders included the different departments of municipalities, citizens, non-governmental organizations, organizations, and the private sector.

The above-mentioned determinants were ranked in the thematic analysis with reference to a qualitative graded scale, according to the number and type of references which were made to them. The authors' expert opinion deriving from long-term involvement with professional planning practice was also conducive to this evaluation:

- none: when the determinant is not mentioned at all; 
- weak: when indirect or scattered references were made to the determinant, with only vague connection to spatial planning;

- good: when explicit references to the determinant were made in the strategy with direct connection to spatial planning.

Based on this ranking, it was possible to conduct a qualitative evaluation of each of the Resilience Strategies and to compare them to one another in order to identify the contribution of each to adaptation to climate change. Thus, the aforementioned determinants function as essential qualitative indicators of resilience, adaptation, sustainability, and planning initiatives $[5,6,35]$. They can also be used for the evaluation of other strategies.

\section{Analysis of the Resilience Strategies of European Cities: Main Findings}

\subsection{Vejle's Resilience Strategy}

Vejle's Resilience Strategy (2016-2020), was the first of this kind to be developed in Denmark and in Europe. Although it does not refer to the term "green infrastructure" or any other equivalent term, it does contain measures that could contribute to adaptation to climate change through the creation of GI. The strategy recognizes both floods due to rising sea levels and increasing rainfall and climate change in general as significant risks.

One of the strategy's initiatives has been to plan a "cycle super-highway" through central Vejle. This measure aims to reduce traffic congestion, to increase green transport mobility, and to facilitate a more active lifestyle for citizens. Yet, it could also be used to improve the connectivity among GI assets and thus become a backbone for the implementation of GI in the city. In conjunction, the installation of permeable paving has been proposed. This could contribute to the creation of GI corridors and could also improve water drainage systems during heavy rainfall. Moreover, the Rosborg district at the edge of the city is targeted for development as a green city, with good links to both the city and nature. Furthermore, this development could address potential shocks and chronic stresses, such as climate change, and test innovative solutions for developing greenfield and derelict land. These could then be chalked up as examples of best practice around cities. Another action proposed in the strategy is to develop the neighboring Vestbyen West City as a "Resilience Laboratory", with a focus on green areas, allotments, water, and flooding. The area already contains several urban gardens. This project aims to strengthen social cohesion, but it could also become a part of the GI assets network, especially if it is linked to the project in Rosborg. Another project which provides opportunities for GI is one in the harbor district of Fjordbyen, where the strategy's ambition is to improve water drainage systems in order to address flooding from the fjord. It also aims to facilitate adaption to climate change by exploring innovative and integrated solutions, such as the retrofitting of new public spaces. Finally, the proposals for the mapping and planning of an overall "leisure and nature" network and for the implementation of the Natura 2000 action plans for the protection of fauna and flora would use biodiversity and community gardening as a way of bringing communities together, and may also enhance GI.

The co-benefits of GI are promoted by the actions which affect GI assets, while participation and collaboration among different stakeholders are evident in most of these actions. However, connectivity among the aforementioned GI assets is absent, and there are only weak links between the assets themselves and the tackling of climate hazards (Table 2). 
Table 2. Evaluation of Vejle's Resilience Strategy.

\begin{tabular}{|c|c|c|c|c|c|c|}
\hline & \multirow{2}{*}{\multicolumn{3}{|c|}{ Determinants }} & \multicolumn{3}{|c|}{ Evaluation } \\
\hline & & & & \multirow[t]{2}{*}{ none } & \multirow{2}{*}{$\begin{array}{c}\text { weak } \\
\sqrt{ }\end{array}$} & \multirow[t]{2}{*}{ good } \\
\hline & \multirow{5}{*}{$\begin{array}{l}\text { physical spatial } \\
\text { planning } \\
\text { perspective }\end{array}$} & \multicolumn{2}{|c|}{ sustaining and enhancing GI assets } & & & \\
\hline & & \multicolumn{2}{|c|}{ connectivity } & $\sqrt{ }$ & & \\
\hline & & \multicolumn{2}{|c|}{ diversity } & & $\sqrt{ }$ & \\
\hline & & \multicolumn{2}{|c|}{ multifunctionality } & & $\sqrt{ }$ & \\
\hline & & \multicolumn{2}{|c|}{ co-benefits } & & & $\sqrt{ }$ \\
\hline \multirow{6}{*}{$\begin{array}{c}\text { identified } \\
\text { exposure(s) by } \\
\text { the strategy: } \\
\text { floods }\end{array}$} & \multirow{5}{*}{$\begin{array}{c}\text { institutions and } \\
\text { governance } \\
\text { perspective }\end{array}$} & \multirow{3}{*}{$\begin{array}{l}\text { learning/ } \\
\text { knowledge }\end{array}$} & from others & & $\sqrt{ }$ & \\
\hline & & & $\begin{array}{c}\text { share/generate } \\
\text { knowledge and best } \\
\text { practices }\end{array}$ & & $\sqrt{ }$ & \\
\hline & & & $\begin{array}{l}\text { public information- } \\
\text { education/awareness }\end{array}$ & & $\sqrt{ }$ & \\
\hline & & governance & $\begin{array}{l}\text { participation and } \\
\text { collaboration }\end{array}$ & & & $\sqrt{ }$ \\
\hline & & & $\begin{array}{l}\text { multi-level } \\
\text { governance }\end{array}$ & & & $\sqrt{ }$ \\
\hline & correlatio & etween hazar & and GI assets & & $\sqrt{ }$ & \\
\hline
\end{tabular}

\subsection{Rotterdam's Resilience Strategy}

In Rotterdam's Resilience Strategy (2016-2030), increases in the average temperature, rainfall/winter precipitation, dry periods, sea level rise, and Rhine river discharges are all identified as stresses caused by climate change affecting the entire country of Netherlands. As with the Vejle strategy, Rotterdam's strategy does not mention the term GI, but it includes projects and actions that foster the creation and enhancement of GI assets.

One relevant ongoing initiative included in the strategy is the transformation of the Zomerhofkwartier (Zoho) district. Another policy program concerns the implementation of green roofs, an important GI asset, across the city center. The action "Smart Schouwburgplein 7 Square Endeavor", as part of the international 7 Square Endeavour Initiative, aims, among other things, to facilitate water storage, and hence contributes to the creation of GI assets. The implementation plan for the development of the Park 1943 area is another new action that aims to enhance the resilience of the whole neighborhood. Among its goals is the more efficient use of gardens and open spaces, as well as the creation of water asset and green areas. Finally, the residential renovation project of the Peperklip apartment block provides an opportunity for the formation of GI, as it is planned to create roof gardens, a semi-public courtyard, public spaces, and gardens while enabling the buffering and reuse of water.

Most of the above initiatives promote the multifunctionality of potential GI assets, and, apart from environmental benefits, also facilitate the provision of social and economic co-benefits. In almost every action, participation and collaboration among a range of stakeholders, including citizens, is encouraged. Particular emphasis is placed on generating and sharing knowledge. This strategy actually builds upon previously gained experience and aims to develop new and enhance existing programs. Moreover, the highlighting of both the knowledge and experience gained and the lessons learned from these experiences allows for the application of such actions in other districts, both in the Netherlands and internationally.

The main deficiency of the strategy is the absence of any connection between these projects. Furthermore, existing networks that could provide connectivity, such as bicycle and pedestrian networks, are not even mentioned. The incomplete analysis and presentation of the projects is another weakness of the strategy, as a number of inputs connected to the implementation of GI are not mentioned. A typical example is the project for the transformation of the Zoho district into a green 
neighborhood. In this project, rain gardens, green roofs and rooftop farms, the greening of the facades (vertical gardens or living walls) and sidewalks, residential back and front gardens, and green public spaces are all measures proposed for the formation of a green structure. These measures would also confront the effects of heavy rainfall, which results in flooding and longer periods of drought and heat stress. However, the strategy makes no mention of the actions above, making reference only to the well-known water square of Waterplein Benthemplein, which can hold water by infiltration and local storage. Finally, although tackling floods through GI assets is promoted, there is no correlation made between urban heating and GI, even though increased temperatures are identified as a stress (Table 3).

Table 3. Evaluation of Rotterdam's Resilience Strategy.

\begin{tabular}{|c|c|c|c|c|c|c|}
\hline & & \multirow{2}{*}{\multicolumn{2}{|c|}{ Determinants }} & \multicolumn{3}{|c|}{ Evaluation } \\
\hline & & & & \multirow{2}{*}{ none } & \multirow{2}{*}{ weak } & \multirow{2}{*}{$\frac{\text { good }}{\sqrt{ }}$} \\
\hline & \multirow{5}{*}{$\begin{array}{l}\text { physical spatial } \\
\text { planning } \\
\text { perspective }\end{array}$} & \multicolumn{2}{|c|}{ sustaining and enhancing GI assets } & & & \\
\hline & & \multicolumn{2}{|c|}{ connectivity } & $\sqrt{ }$ & & \\
\hline & & \multicolumn{2}{|c|}{ diversity } & & $\sqrt{ }$ & \\
\hline & & \multicolumn{2}{|c|}{ multifunctionality } & & & $\sqrt{ }$ \\
\hline \multirow{7}{*}{$\begin{array}{c}\text { identified } \\
\text { exposure(s) by } \\
\text { the strategy: } \\
\text { urban heat and } \\
\text { floods }\end{array}$} & & \multicolumn{2}{|c|}{ co-benefits } & & & $\sqrt{ }$ \\
\hline & \multirow{5}{*}{$\begin{array}{l}\text { institutions and } \\
\text { governance } \\
\text { perspective }\end{array}$} & \multirow{3}{*}{$\begin{array}{l}\text { learning/ } \\
\text { knowledge }\end{array}$} & from others & & & $\sqrt{ }$ \\
\hline & & & $\begin{array}{c}\text { share/generate } \\
\text { knowledge and best } \\
\text { practices }\end{array}$ & & & $\sqrt{ }$ \\
\hline & & & $\begin{array}{l}\text { public information- } \\
\text { education/awareness }\end{array}$ & & $\sqrt{ }$ & \\
\hline & & \multirow{2}{*}{ governance } & $\begin{array}{l}\text { participation and } \\
\text { collaboration }\end{array}$ & & & $\sqrt{ }$ \\
\hline & & & $\begin{array}{l}\text { multi-level } \\
\text { governance }\end{array}$ & & & $\sqrt{ }$ \\
\hline & \multicolumn{3}{|c|}{ correlation between hazards and GI assets } & & $\sqrt{ }$ & \\
\hline
\end{tabular}

\subsection{Glasgow's Resilience Strategy}

Glasgow's Resilience Strategy was the first one in Europe to use the term GI. The strategy was designed to be implemented during the period 2016-2018, and subsequently would be revised. The strategy pinpoints mainly social issues as the major resilience challenge, but it also identifies increased rainfall, flooding, and extreme weather events as well as changes in temperature as risks. On examination, it appears that this strategy refers only briefly to GI assets. One of the ongoing projects mentioned is "Stalled Spaces", which focuses on the temporary use of vacant land and under-utilized open spaces for developments such as green gyms, active play, and spaces for urban farming.

In relation to the second key pillar of the strategy, both the aim of community access to green affordable means of transport along with the aim of good access to physical infrastructure are mentioned. One of the goals connected with this strategic pillar concerns the north part of the city and its transformation into a "resilience exemplar" district. In order to achieve this transformation, different types of GI assets, such as the extensive areas of green space, derelict and vacant sites, the Forth and Clyde Canal, and the athletes' village, will all be taken into consideration. The athletes' village is considered an exemplar "eco-village". Measures to achieve this transformation and to address the local impacts of global climate change, particularly the impacts of increased rainfall and flooding, will include the implementation of sustainable water management solutions, such as open channels, ponds, and rain gardens. The strategy also recognizes that this GI will not only upgrade the city's water drainage infrastructure but will also provide social, economic, and environmental advantages. Moreover, waterway reconnections and blue-green networks are among the measures envisaged for managing rainfall, flooding, and the improvement of water quality. 
This strategy promotes the environmental, social, and economic co-benefits that GI assets can provide, also addressing the risk of floods. In addition, it is proposed that the knowledge of best practices gleaned from other member cities of 100RC be utilized, thereby enhancing collaboration among different stakeholders. The strategy's main weakness is the absence of the concept of connectivity. This may derive from the fact that, even though the strategy integrates and promotes already existing partnerships, projects, and strategies which support and implement the concept of GI, these are only mentioned without being analyzed. Thus, the references to the Stalled Spaces project, the Glasgow and Clyde Valley Green Network Partnership, the Climate Ready Clyde initiative, and the Open Space Strategy are incomplete, as great opportunities for deriving valuable lessons from these projects are missed (Table 4).

Table 4. Evaluation of Glasgow's Resilience Strategy.

\begin{tabular}{|c|c|c|c|c|c|c|}
\hline & \multirow{2}{*}{\multicolumn{3}{|c|}{ Determinants }} & \multicolumn{3}{|c|}{ Evaluation } \\
\hline & & & & \multirow[t]{2}{*}{ none } & \multirow{2}{*}{$\frac{\text { weak }}{\sqrt{ }}$} & \multirow[t]{2}{*}{ good } \\
\hline & \multirow{5}{*}{$\begin{array}{l}\text { physical spatial } \\
\text { planning } \\
\text { perspective }\end{array}$} & \multicolumn{2}{|c|}{ sustaining and enhancing GI assets } & & & \\
\hline & & \multicolumn{2}{|c|}{ connectivity } & $\sqrt{ }$ & & \\
\hline & & \multicolumn{2}{|c|}{ diversity } & & $\sqrt{ }$ & \\
\hline & & \multicolumn{2}{|c|}{ multifunctionality } & $\sqrt{ }$ & & \\
\hline \multirow{7}{*}{$\begin{array}{c}\text { identified } \\
\text { exposure(s) by } \\
\text { the strategy: } \\
\text { floods }\end{array}$} & & \multicolumn{2}{|c|}{ co-benefits } & & & $\sqrt{ }$ \\
\hline & \multirow{5}{*}{$\begin{array}{l}\text { institutions and } \\
\text { governance } \\
\text { perspective }\end{array}$} & \multirow{3}{*}{$\begin{array}{l}\text { learning/ } \\
\text { knowledge }\end{array}$} & from others & & & $\sqrt{ }$ \\
\hline & & & $\begin{array}{c}\text { share/generate } \\
\text { knowledge and best } \\
\text { practices }\end{array}$ & $\sqrt{ }$ & & \\
\hline & & & $\begin{array}{l}\text { public information- } \\
\text { education/awareness }\end{array}$ & $\sqrt{ }$ & & \\
\hline & & governance & $\begin{array}{l}\text { participation and } \\
\text { collaboration }\end{array}$ & & $\sqrt{ }$ & \\
\hline & & gоvertiante & $\begin{array}{l}\text { multi-level } \\
\text { governance }\end{array}$ & & & $\sqrt{ }$ \\
\hline & correlatior & etween hazar & and GI assets & & & $\sqrt{ }$ \\
\hline
\end{tabular}

\subsection{Thessaloniki's Resilience Strategy}

In Thessaloniki's Resilience Strategy (2017-2030), some of the most serious challenges highlighted are high summer temperatures (heat waves), very heavy rainfall, and urban floods. Furthermore, green open spaces are limited in number and fragmented. There is also a high level of car dependency. The strategy refers briefly to the importance of both the waterfront and the Thermaikos Bay natural resources and their significance for the city. This strategy does mention the term GI, although there is no clear integration shown between it and the strategy's goals and actions.

Measures to tackle mobility problems relevant to GI goals include, amongst others, the construction of a new metropolitan bike lane network. Furthermore, the proposed connection of bike lanes with the waterfront and with the city's east Peripheral Trench and the pedestrian zones is also significant. The bike lanes would run parallel to the metro stations and archaeological sites.

In order to adapt to climate change and specifically to tackle UHI and storm water, the utilization of existing open spaces is stressed along with the creation of GI. It is proposed that a range of different GI assets, such as permeable surfaces, a rain gardens/bioswale sidewalk network, and green roofs and walls, be linked to cultural and leisure sites and bike lanes. Other measures promote the creation of pocket parks; the use of school grounds as open spaces; urban agriculture in inner courtyards; and turning private balconies, vacant land, and rooftops into gardens, along with the maintenance of the existing community garden. It is not evident if these last assets are included in the previously mentioned network. Additional measures to address floods include the utilization of the city's west 
Peripheral Trench as well as of secondary streams. The last of the strategy's four goals is connected exclusively to the Thermaikos Bay, which is considered to be a GI asset anyway. One objective within this fourth goal is the restoration of the natural beaches. However, their interrelationship with other GI assets is not mentioned. Lastly, the connection of the waterfront with the cultural assets of the municipalities through bike and pedestrian lanes is highlighted.

While this strategy promotes the creation of GI asset networks, the nature of the interconnectivity between these networks is not really clear. An analysis of their connection with other important GI assets in neighboring municipalities is also missing, and only a brief mention is made to private GI assets. Emphasis is given to the co-benefits GI assets can provide (with economic benefits getting less attention), and while it is proposed that the stresses and shocks identified are to be addressed through GI assets, the multi-functionality of the spaces themselves is not apparent. The collaboration and participation of different stakeholders at different levels, including citizens, is generally promoted, and so is the education and informing of citizens (Table 5).

Table 5. Evaluation of Thessaloniki's Resilience Strategy.

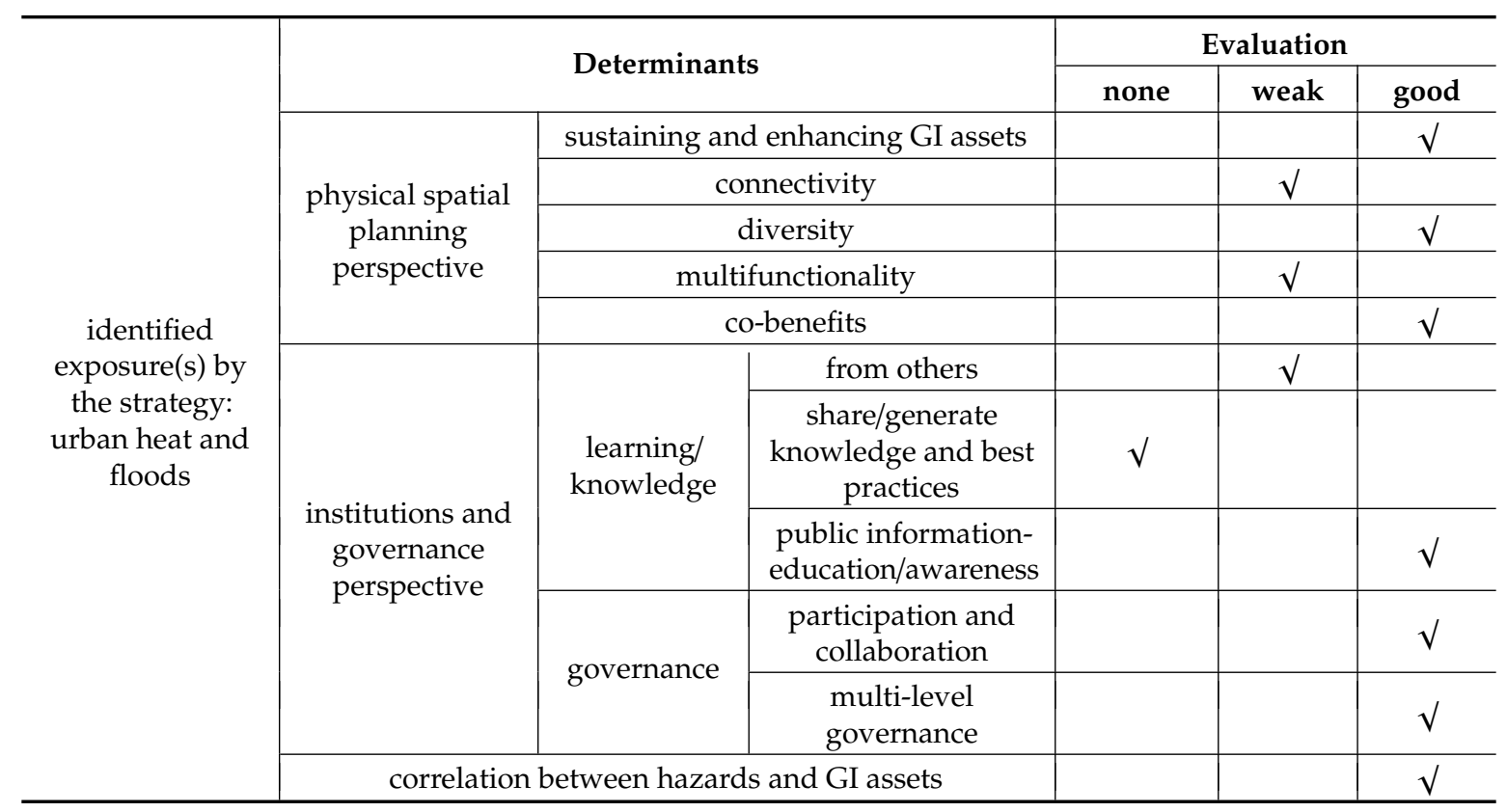

\subsection{Athens' Resilience Strategy}

Athens' Resilience Strategy (2017-2030) directly links the enhancement of resilience to both the creation and the revitalization of open and green public spaces and, more specifically, to what it calls the city's "green and blue infrastructures". Increased temperatures and heat waves, which intensify the city's UHI effect, and floods and bad air quality are all identified as major shocks and threats. The factors cited as contributing to this situation include the urban layout pattern and form, including the lack of green open spaces, the low quality and dispersed pattern of existing spaces, the depletion of the peri-urban green, the large non-water permeable area, and the covering of the majority of the natural water network. The strategy states that all these problems can be attributed chiefly to the absence of integrated planning.

The strategy promotes the maintenance and creation of a range of GI assets, both public and private, along with the formation of corridors and networks. However, the main deficiency of this strategy is that the connectivity among all these assets and networks is not really clear (especially for someone that does not know the city), and so in this aspect it seems to be rather patchy. Moreover, significant projects related to GI, such as the triple green development project, the Elaionas project, the old train stations' refurbishment, and the expropriation and greening of abandoned lots, are not connected with 
the proposed networks. Thus, opportunities for designing and implementing GI are not enhanced. However, among all the strategies examined, this one does seem to demonstrate the most integrated approach regarding connectivity. Although the co-benefits are not emphasized as much as in the other strategies, it is significant that the economic benefits are mentioned. Furthermore, the implementation of specific measures could facilitate the multi-functionality of the areas in question. A typical example would be the suggestion to launch food gardens and street markets in existing schoolyards.

On the other hand, other components generally considered to be fundamental components for the successful implementation of the measures within the strategy, such as the informed awareness of citizens and the private sector, along with their involvement and participation in the implementation of these GI measures, are not really apparent. Thus, there is much room for improvement and the active engagement of individuals. On a more positive note, best practices from and successful measures implemented in other cities seem to be utilized. Cooperation among different stakeholders of different scales is also promoted to a great extent. Generally, the strategy seems to utilize GI assets in order to tackle climate change impacts and also to achieve social and economic benefits (Table 6).

Table 6. Evaluation of Athens' Resilience Strategy.

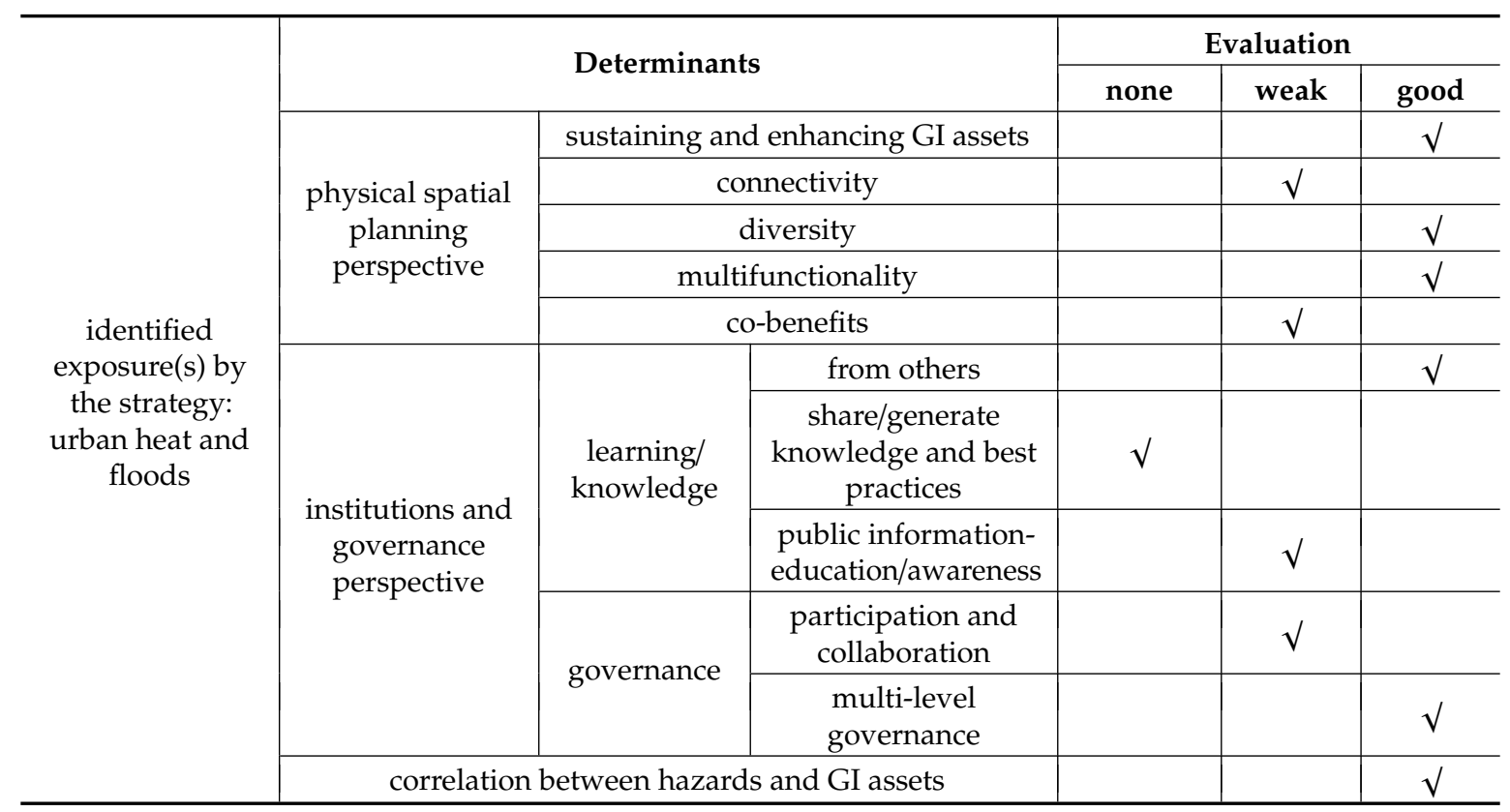

\subsection{Paris' Resilience Strategy}

The Paris' Resilience Strategy (released in 2017) identifies heat waves, droughts, extremely heavy rainfall, storms, flooding, and water scarcity as the main climate change risks caused by the rise in average temperature, in combination with the UHI effect and air pollution. It is clearly stated that these stresses accelerate the degradation of the natural environment. Therefore, adaptation along with mitigation is necessary in order to address the already visible climate change impacts in Paris.

As with the above strategies, the term GI is not mentioned in this strategy. However, some of the strategies' measures and projects already carried out relate to GI and contribute to resilience and adaptation. The strategy emphasizes that public spaces should facilitate multiple uses, provide training, and engage the community. However, some of these measures do not explicitly refer to open spaces but to buildings. Nevertheless, one of the measures, based on the initiatives of the Climate Change Adaptation Strategy, aims to transform schoolyards by replacing asphalt walkways with trees and vegetation. It also encourages innovative learning through the testing of new materials, some of which can be used to provide urban cooling. Moreover, the transformation of public spaces, which improve quality of life, aided by the participation of citizens is also promoted. 
One set of measures which concern road infrastructure indicate the incorporation of environmental concerns into planning so that multiple purposes can be achieved. These measures include the installation of paving material to reduce the UHI effect, the construction of cycle paths, the drainage of structures, the storage of rainwater underground, the grassing of pavers, and the incorporation of grass strips and planters, along with attention to cultural activities, sport, and soft mobility. The transformation of the ring road (Périphérique), which entails the earmarking of specific sections for the use of pedestrians and cyclists, has also been initiated. Generally, the strategy promotes the reclamation of urban spaces currently occupied by road traffic as one of the ways to improve air quality.

The design of two parks is proposed, with the involvement of the local community throughout the whole process of the project. This measure aims to provide multifunctionality and co-benefits, such as the re-use rainwater, the tackling of UHI, the enhancement of biodiversity, the provision of amenities for social interaction, and the accommodation of cultural and artistic events. The strategy also foresees the utilization of rooftops as open and shared spaces for neighbors to organize leisure events. This utilization could also contribute to urban agriculture, greening, and cooling, increasing solar energy production and rainwater storage and making use of vacant and idle spaces. The strategy states that the city of Paris will encourage and support both individual citizens and private actors/companies to utilize their GI assets-namely, walls, roofs, balconies, inner courtyards, and parking places-to increase green spaces. It will also support the harvesting of rainwater and facilitate the use of rain barrels. It is worth mentioning that, apart from the previously mentioned privately owned GI assets, the city of Paris has already launched an initiative for the utilization of public areas which are not currently maintained as green spaces. Through this "greening permit", people will have the opportunity to get involved in greening their city. Urban agriculture is also promoted through the formation of a sustainable food production strategy, which involves the development of the first resilient and climate-sensitive neighborhood of Saint-Vincent-de-Paul, and the already established " 100 hectares objective" charter initiative. The latter has envisaged the green coverage of buildings by 2020, with 30 of the 100 hectares devoted to urban agriculture. This same initiative will also finance the "Parisculteurs" call for projects.

The strategy also raises awareness in regard to flooding and incorporates natural solutions to the problem, such as ensuring the permeability of soils, the renaturation of the riverbed of the Seine and its tributaries where possible, the expansion of the flood zone, and the redevelopment of biodiversity and wetlands. One example of these solutions would be the design of an exemplary resilient neighborhood in a brownfield redevelopment area. This development will take place at Bercy-Charenton, which is partially located in a flood zone. The strategy also identifies both the multifunctional nature of the co-benefits, such as increased water supply, biodiversity, recreation, cooling, flood, and low-water prevention and decontamination provided by the river Seine. These benefits will also emerge through partnerships and cooperation with neighboring territories and regional organization.

Overall, the Paris Resilience Strategy foresees the creation, conservation, and enhancement of quite a wide range of GI assets. The participation of citizens is given a highly priority, and training, the dissemination of public information, and continued international knowledge exchange are all promoted throughout the strategy. Although these practices are not really apparent in the measures proposed for GI, the best practices, projects, and policies already implemented by other member cities of 100RC seem to be taken into account. On the other hand, even though the challenge of correct governance is stated as being a priority within this strategy, multi-level governance in GI is not always clear. The collaboration of different stakeholders, private and public, is proposed, but the precise nature of this collaboration is not always mentioned, and so it is not clear whether and how they could participate in the design and implementation of the measures. While the strategy seemingly facilitates GI's multifunctionality and co-benefits, it is clear that neither the specifics of this provision nor the potential economic benefits of it are specified or discussed. The main deficiency of this strategy is the complete absence of the notion of connectivity among the GI assets, which is a fundamental feature of GI. However, the strategy does address most of the identified hazards through GI assets (Table 7). 
Table 7. Evaluation of Paris' Resilience Strategy.

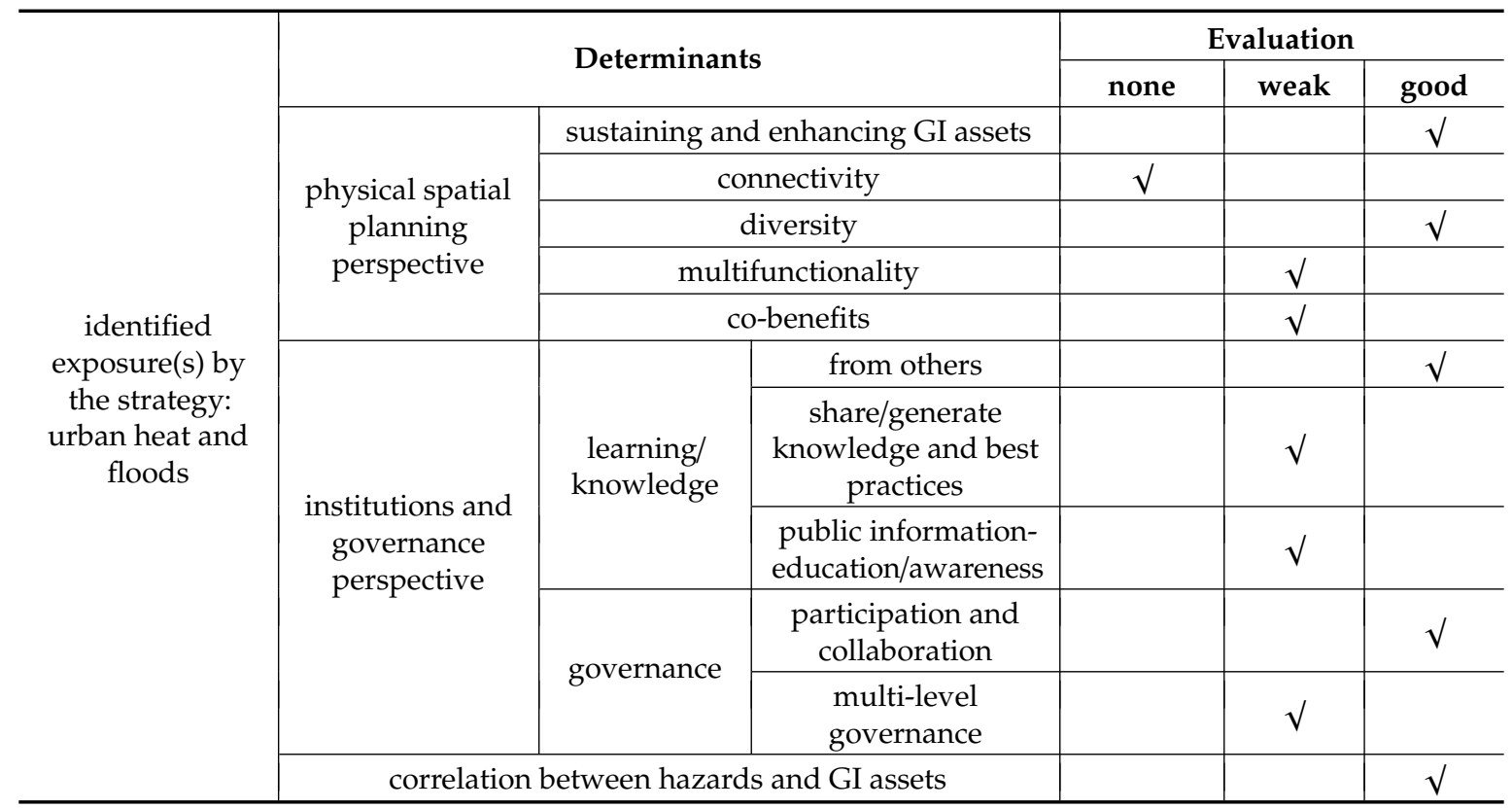

\subsection{Rome's Resilience Strategy}

Rome's Resilience Strategy (released in 2018) uses the term "green and blue infrastructure". Heat islands and floods, including flash and river floods, as well as those due to bad surface water runoff, along with decreased rainfalls, drought, and landslides, are all identified as major climate change risks. A variety of GI assets are mentioned in the strategy, from the Tiber and the coastline, to farms, and Natural Protected Areas. Urban assets, such as parks, green rooftops, urban and rain gardens, food forests, and floodable squares are also mentioned. The strategy focuses on both public and private assets. The strategy's measures promote the creation, protection, preservation, maintenance, enhancement, and re-development of these assets. However, the principle of connectivity among them is weak. The strategy apparently promotes the preservation of the existing ecological network and the creation of a pedestrian and cycling network, along with the already implemented redevelopment of a number of parks along the banks of the River Tiber. Yet, the connection between these various GI assets is not apparent. The multifunctionality of the GI assets and the co-benefits they can provide are envisaged as developing mainly through environmental, cultural, sports, and farming activities. In relation to farming and urban forestry-gardening activities, the fact that the economic benefits are also considered is significant.

Rome's strategy utilization of the knowledge of best practices, measures taken, and tools used in other member cities' Resilience Strategies is commendable, as is the utilization of experience gained from projects developed in collaboration with the Rockefeller Foundation. Moreover, raising citizens' awareness of environmental matters and the effects of climate change is given a high priority. However, although the generation of knowledge is encouraged through learning from the farming sector, this knowledge generation is not pursued in other measures related to GI. While the strategy mentions the voluntary participation of citizens in the various plans and projects, this is not elaborated upon. The same applies to the multilevel collaboration of all the stakeholders. Even though synergies among stakeholders have been proposed or conducted, the degree of collaboration between different departments, as well as between public and private stakeholders, seems to be limited. It is worth mentioning that the strategy does acknowledge the importance of the involvement of public and private and local and international stakeholders. This involvement may contribute to the enhancement of the multilevel characteristic of governance. Overall, the tackling of climate hazards through GI assets is very apparent throughout the strategy (Table 8). 
Table 8. Evaluation of Rome's Resilience Strategy.

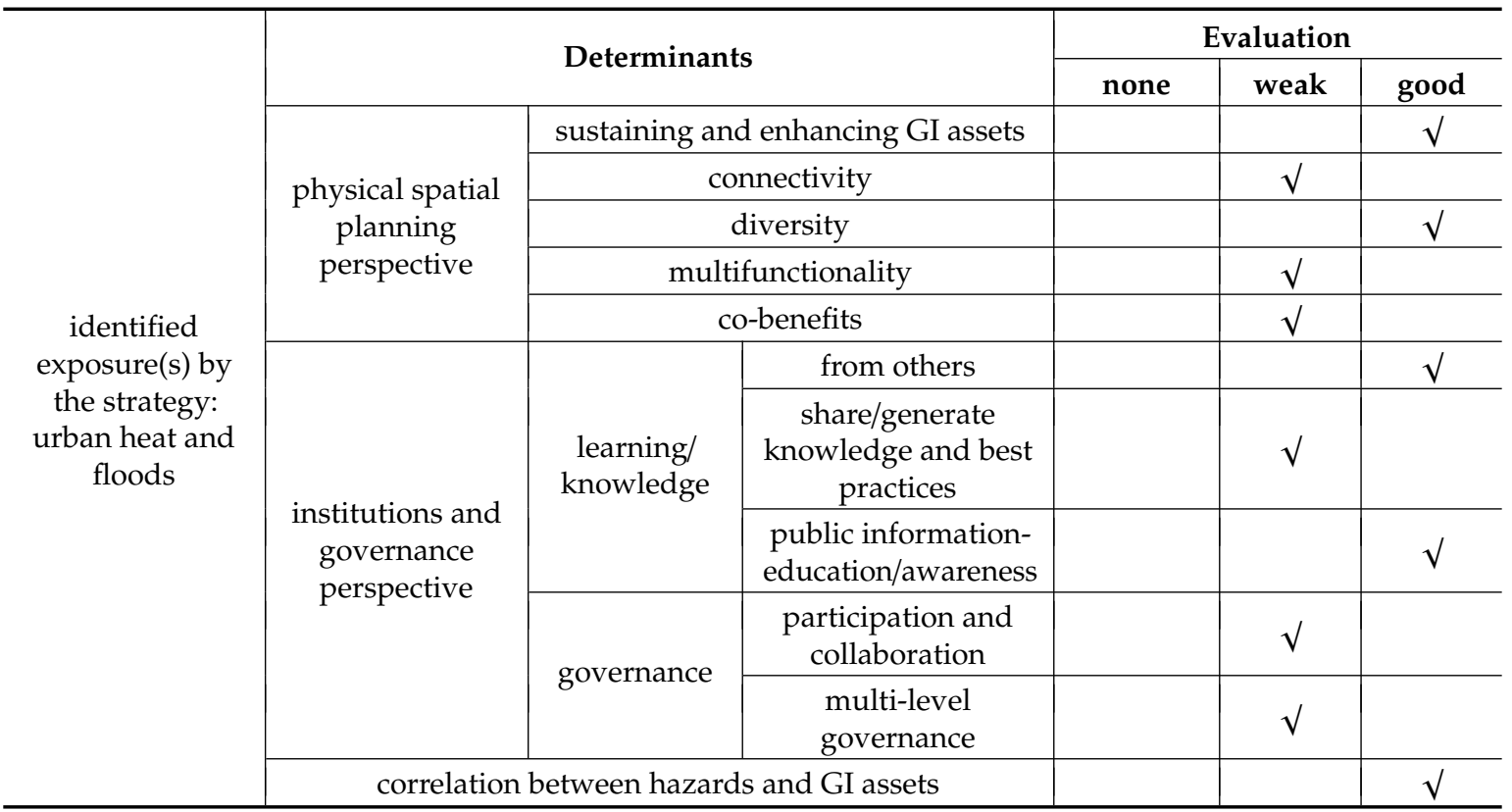

\section{Discussion}

The study of the European Resilience Strategies of the 100RC initiative (pioneered by the Rockefeller Foundation) provided plenty of material for an investigation into whether and how city strategies facilitate the application of spatial planning principles and measures towards the process of adaptation to climate change. A qualitative methodology was used to make a comparative analysis of seven Resilience Strategies of respective European cities in order to demonstrate whether specific planning tools were deliberately integrated into the general goal of adaptation. The present study focused on the ecosystem-based planning tool of GI and intended to reveal whether these planning tools were treated as an integral part of the strategy or, alternatively, whether they were considered as being part of a loosely connected but distinct field. Figure 2 illustrates a synthetic and comparative assessment of the selected determinants for all the strategies under study.

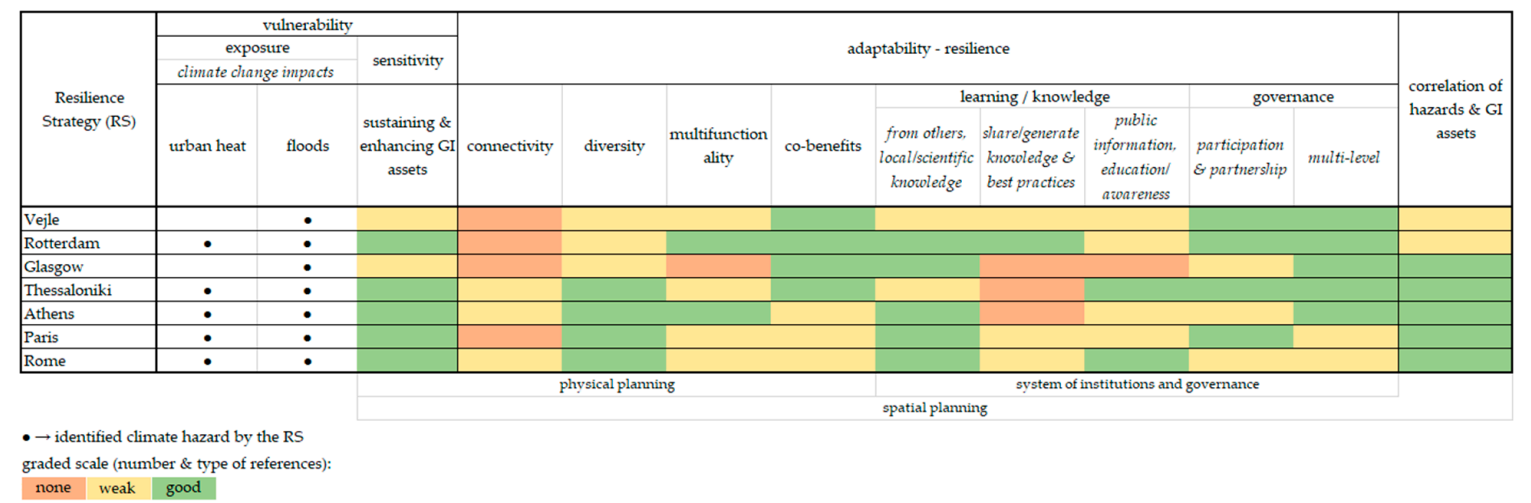

Figure 2. Comparative assessment of selected determinants in the 7 European Resilience Strategies.

All the cities apart from Vejle and Glasgow identified both urban heating and floods as significant climate hazards. In Vejle's and Glasgow's strategies, although climate change is recognized as a stressor, there is no explicit mention of increased urban temperature. It should also be noted that, even though many of the strategies also address the climate change impact of the potentially reduced availability of food and water, this issue is not addressed in this paper. 
Regarding the diversity of GI assets, although most of the strategies examined incorporated a variety of different assets, there are some important ones which are not included, such as former camps, institutional open spaces, play areas, streams, cemeteries, woodlands, forests, nature reserves, agricultural land, etc., These assets would also contribute to increased connectivity within the GI, and thus to a formation of GI networks. Furthermore, even though co-benefits are mentioned in measures promoting GI assets, this is largely notional, as there is no actual analysis of how these benefits could be realized.

The generation of knowledge and best practices along with the dissemination of public information and education are two fields that need enhancement. However, the most serious deficiency of all the strategies is the absence of the concept of connectivity among GI assets. This applies both to those assets inside the urban fabric and to those of peri-urban areas. The absence of this connectivity cannot be ignored, as it actually forms the backbone of the theoretical construction as well as the implementation of GI.

Overall, none of the strategies actually fully incorporates the concept of GI, as within each of them a number of its key planning principles are missing. Thus, the multiple benefits that could be provided by GI assets are not fully exploited, and hence an important means of achieving adaptation and, moreover, sustainability, is left unexploited. Even though many of the strategies refer to their city's adaptation strategy, a more efficient correlation between the two strategies may be needed. Furthermore, it is noteworthy that only for a very few of the adaptation measures examined are there any projections for long-term monitoring or updating.

Finally, it should be pointed out that there is still room for improvement in all the strategies. Given that the 100RC program was finalized in July 2019, these improvements could be made through the redefining of measures to be taken during the implementation and monitoring phases. Further improvement could be made through the continued support of the cities and their Chief Resilience Officers by the Global Resilient Cities Network, which emerged from the 100RC program.

\section{Conclusions}

The quest for adaptation to climate change and, eventually, for the sustainability of cities, increases the need to promote the implementation of effective policies and tools in the specific strategies that each city adopts. These strategies should be better informed than they are at present of the way in which these tools are interconnected with the concepts of vulnerability, adaptability, and resilience. Hence, they should be better informed of the interconnection between the tools and the overall goal of adaptation. The incorporation of a spatial planning angle in such strategies is of critical importance if the cities are to achieve these goals. This is due to the fact that spatial planning can regulate the availability, physical form, and use of both built up and open/green areas, as well as their interconnectivity. It is commonly acknowledged that the promising ecosystem-based tool of GI, essentially a spatial planning tool, provides multiple benefits and can reduce the vulnerability of cities, increase their resilience, and essentially facilitate their adaptation to climate change. Over the last 5 years, various Resilience Strategies have specifically accentuated the GI planning tool, adopting, preparing, and placing it on their public agenda.

The main lessons learnt from the current investigation are that these kinds of city strategies, although they easily adopt ecosystem-based tools, such as GI, often lack a concrete understanding of the way these tools operate. As a result, these proposed tools have inherent ambiguities, a fact that makes it difficult to apply them in practice. Therefore, an important issue raised in this paper is that, in order to avoid haziness and generality, it is necessary for these strategies to focus more consciously and more effectively on the determining factors of the GI tool and utilize feedback from different disciplines. This paper has proposed a methodological framework for defining these factors, relating them to both critical angles of spatial planning: first, to the physical angle, which secures diversity, connectivity, redundancy, flexibility, and modularization; and second to the institutional one, which gives prominence to learning and knowledge, participation and partnership, multi-level 
governance, and complex adaptive system thinking. Using this framework would make city strategies more concrete, providing deeper insight for decision makers, planners, and other involved parties who are called on to implement them into practice.

Additional research into other Resilience Strategies from different cities around the world would throw more light on the proposed methodology and the evaluation framework. Based on such a framework, the cities' strategies could improve their own methods of increasing local/expert knowledge and raise their awareness of effective measures and policies, thereby widening the range of multidimensional benefits and the co-benefits that nature-based solutions promote. These are solutions which would help to achieve adaptation to climate change.

Author Contributions: Conceptualization, K.-D.S. and A.Y.; methodology, K.-D.S. and A.Y.; investigation, K.-D.S.; supervision, A.Y.; writing-original draft preparation K.-D.S. and A.Y.; writing-review and editing, K.-D.S. and A.Y. All authors have read and agreed to the published version of the manuscript.

Funding: This research received no external funding.

Conflicts of Interest: The authors declare no conflict of interest.

\section{References}

1. Leichenko, R. Climate change and urban resilience. Curr. Opin. Environ. Sustain. 2011, 3, 164-168. [CrossRef]

2. Davoudi, S.; Shaw, K.; Haider, L.J.; Quinlan, A.E.; Peterson, G.D.; Wilkinson, C.; Fünfgeld, H.; McEvoy, D.; Porter, L.; Davoudi, S. Resilience: A Bridging Concept or a Dead End? "Reframing" Resilience: Challenges for Planning Theory and Practice Interacting Traps: Resilience Assessment of a Pasture Management System in Northern Afghanistan Urban Resilience: What Does it Mean in Planning Practice? Resilience as a Useful Concept for Climate Change Adaptation? The Politics of Resilience for Planning: A Cautionary Note. Plan. Theory Pract. 2012, 13, 299-333. [CrossRef]

3. Davoudi, S.; Brooks, E.; Mehmood, A. Evolutionary Resilience and Strategies for Climate Adaptation. Plan. Pract. Res. 2013, 28, 307-322. Available online: https://doi.org/10.1080/02697459.2013.787695 (accessed on 15 April 2020). [CrossRef]

4. Woodruff, S.C.; Meerow, S.; Stults, M.; Wilkins, C. Adaptation to Resilience Planning: Alternative Pathways to Prepare for Climate Change. J. Plan. Edu. Res. 2018. [CrossRef]

5. Brown, C.; Shaker, R.R.; Das, R. A review of approaches for monitoring and evaluation of urban climate resilience initiatives. Environ. Develop. Sustain. 2018, 20, 23-40. [CrossRef]

6. Shaker, R.R.; Rybarczyk, G.; Brown, C.; Papp, V.; Alkins, S. (Re) emphasizing Urban Infrastructure Resilience via Scoping Review and Content Analysis. Urban Sci. 2019, 3, 44. [CrossRef]

7. Meerow, S.; Stults, M. Comparing Conceptualizations of Urban Climate Resilience in Theory and Practice. Sustainability 2016, 8, 701. [CrossRef]

8. Rankin, A.; Bång, M.; Sainz, M.; Radianti, J.; Brage, J.; Rosenqvist, S.; Lebaka, L.; Hernantes, J. D1.1 Survey Report on World-Wide Approaches. 2016. Available online: http://smr-project.eu/deliverables/ (accessed on 15 April 2020).

9. Smit, B.; Pilifosova, O. Adaptation to Climate Change in the Context of Sustainable Development and Equity. In Climate Change 2001: Impacts, Adaptation, and Vulnerability - Contribution of Working Group II to the Third Assessment Report of the Intergovernmental Panel on Climate Change; McCarthy, J.J., Canziani, O.F., Leary, N.A., Dokken, D.J., White, K.S., Eds.; Cambridge University Press: Cambridge, UK, 2001; pp. 877-912.

10. Satterthwaite, D.; Dodman, D. Towards resilience and transformation for cities within a finite planet. Environ. Urban. 2013, 25, 291-298. [CrossRef]

11. Brooks, N. Vulnerability, Risk and Adaptation: A Conceptual Framework; Working Paper 38; Tyndall Center for Climate Change Research: Norwich, UK, 2003.

12. Mendis, S.; Mills, S.; Yantz, J. Building Community Capacity to Adapt to Climate Change in Resource-Based Communities; Working Paper; Canadian Forest Service: Saskatoon, SK, Canada, 2003.

13. O'Brien, K.; Eriksen, S.; Schjolden, A.; Nygaard, L.P. What's in a Word? Conflicting Interpretations of Vulnerability in Climate Change Research; Working Paper 2004:04; CICERO: Oslo, Norway, 2004. 
14. Walker, B.; Holling, C.S.; Carpenter, S.R.; Kinzig, A. Resilience, adaptability and transformability in social-ecological systems. Ecol. Soc. 2004, 9, 5. Available online: http://www.ecologyandsociety.org/vol9/ iss2/art5 (accessed on 4 April 2020). [CrossRef]

15. Gallopín, G.C. Linkages between vulnerability, resilience, and adaptive capacity. Glob. Environ. Chang. 2006, 16, 293-303. [CrossRef]

16. Walker, B.H.; Gunderson, L.H.; Kinzig, A.P.; Folke, C.; Carpenter, S.R.; Schultz, L. A handful of heuristics and some propositions for understanding resilience in social-ecological systems. Ecol. Soc. 2006, 11, 13. Available online: http://www.ecologyandsociety.org/vol11/iss1/art13/ (accessed on 4 April 2020). [CrossRef]

17. Nelson, D.R.; Adger, W.N.; Brown, K. Adaptation to Environmental Change: Contributions of a Resilience Framework. Annu. Rev. Environ. Res. 2007, 32, 395-419. [CrossRef]

18. Engles, N. Adaptive capacity and its assessment. Glob. Environ. Chang. 2011, 21, 647-656. [CrossRef]

19. Smit, B.; Wandel, J. Adaptation, adaptive capacity and vulnerability. Glob. Environ. Chang. 2006, 16, $282-292$. [CrossRef]

20. Jabareen, Y. Planning the resilient city: Concepts and strategies for coping with climate change and environmental risk. Cities 2013, 31, 220-229. [CrossRef]

21. Davoudi, S.; Crawford, J.; Mehmood, A. Planning for Climate Change: Strategies for Mitigation and Adaptation for Spatial Planners; Earthscan: London, UK, 2009.

22. Rouse, D.C.; Bunster-Ossa, I.F. Green Infrastructure: A Landscape Approach; Planning Advisory Service Report Number 571; American Planning Association: Chicago, IL, USA, 2013.

23. Lennon, M.; Scott, M. Delivering ecosystems services via spatial planning: Reviewing the possibilities and implications of a green infrastructure approach. Town Plan. Rev. 2014, 85, 563-587. [CrossRef]

24. Schiappacasse, P.; Müller, B. Planning Green Infrastructure as a Source of Urban and Regional Resilience-Towards Institutional Challenges. Urbani Izziv 2015, 26, S13-S24. [CrossRef]

25. Meerow, S.; Newell, J.P. Spatial planning for multifunctional green infrastructure: Growing resilience in Detroit. Landsc. Urban Plan. 2017, 159, 62-75. [CrossRef]

26. Yiannakou, A.; Salata, K.D. Adaptation to Climate Change through Spatial Planning in Compact Urban Areas: A Case Study in the City of Thessaloniki. Sustainability 2017, 9, 271, (Special Issue: Urban Heat Island). [CrossRef]

27. Ahern, J.F. From fail-safe to safe-to-fail: Sustainability and resilience in the new urban world. Landsc. Urban Plan. 2011, 100, 341-343. [CrossRef]

28. Biggs, R.; Schluter, M.; Biggs, D.; Bohensky, E.L.; BurnSilver, S.; Cundill, G.; Dakos, V.; Daw, T.M.; Evans, L.S.; Kotschy, K.; et al. Toward Principles for Enhancing the Resilience of Ecosystem Services. Annu. Rev. Environ. Resour. 2012, 37, 421-448. [CrossRef]

29. Landscape Institute. Green Infrastructure: Connected and Multifunctional Landscape; Position document; Landscape Institute: London, UK, 2009.

30. Natural England. Green Infrastructure Guidance; Natural England: London, UK, 2009.

31. Salata, K.D.; Yiannakou, A. Green Infrastructure and climate change adaptation. Tema J. Land Use. Mobil. Environ. 2016, 9, 7-24. [CrossRef]

32. ESPON. COMPASS-Territorial Governance and Spatial Planning; ESPON: Luxembourg, 2018. Available online: https://www.espon.eu/planning-systems (accessed on 8 July 2020).

33. Braun, V.; Clarke, V. Using thematic analysis in psychology. Qual. Res. Psychol 2006, 3, 77-101. [CrossRef]

34. Callo-Concha, D.; Ewert, F. Using the concepts of resilience, vulnerability and adaptability for the assessment and analysis of agricultural systems. Chang. Adapt. Socio-Ecol. Sys. 2014, 1, 1-11. [CrossRef]

35. Shaker, R.R.; Aversa, J.; Papp, V.; Serre, B.M.; Mackay, B.R. Showcasing Relationships between Neighborhood Design and Wellbeing Toronto Indicators. Sustainability 2020, 12, 997. [CrossRef]

(C) 2020 by the authors. Licensee MDPI, Basel, Switzerland. This article is an open access article distributed under the terms and conditions of the Creative Commons Attribution (CC BY) license (http://creativecommons.org/licenses/by/4.0/). 